Supporting Information

\title{
Efficient Visual Chemosensor for Hexavalent Chromium Via a Controlled Strategy for Signal Amplification in Water
}

Teng Zhang ${ }^{\mathrm{a}}$, Shouting Zhang ${ }^{\mathrm{a}^{*}}$, Jia Liu ${ }^{\mathrm{a}}$, Jing $\mathrm{Li}^{\mathrm{a}}$, Xiaoquan $\mathrm{Lu}^{\mathrm{a}, \mathrm{b}^{*}}$

a Tianjin Key Laboratory of Molecular Optoelectronic, Department of Chemistry, School of Science, Tianjin University, Tianjin, 300072, P. R. China.

${ }^{\mathrm{b}}$ Key Laboratory of Bioelectrochemistry \& Environmental Analysis of Gansu Province, College of Chemistry \& Chemical Engineering, Northwest Normal University, Lanzhou 730070, P. R.China.

*Phone: $+860931-7971276,+86$ 22-83613363.

E-mail: luxq@tju.edu.cn, luxq@nwnu.edu.cn, zhangsht@ @iju.edu.cn; 


\section{Table of contents}

Scheme S1. The synthetic route of $\mathrm{rGO} / \mathrm{PEI} / \mathrm{Au}$ nanohybrids ..S3

Figure S1. (a) TEM image of GO and SAED pattern of GO nanosheets. (b) TEM image of rGO/PEI and SAED pattern of rGO/PEI nanosheets. (c) Dark field STEM image and (d) element mapping images of rGO/PEI nanosheets. (e) Photographs of GO nanosheets and the $\mathrm{rGO} / \mathrm{PEI} / \mathrm{Au}$ nanohybrids in ultrapure water. (f) TEM images of the rGO/PEI/Au nanohybrids.

Figure S2. (a) FT-IR spectrum of GO and rGO-COOH nanohysheets and (b) rGO-PEI nanohysheets and rGO/PEI/Au nanohybrids. (c) XRD patterns of the GO and rGO-COOH nanohysheets and (d) XRD patterns of the rGO/PEI nanohysheets and $\mathrm{rGO} / \mathrm{PEI} / \mathrm{Au}$ nanohybrids

Figure S3. (a) Raman spectra of GO, rGO-COOH and rGO/PEI nanohysheets. (b) TG-DTA spectra of rGO/PEI nanohysheets. (c) XPS wide survey spectra of the rGO/PEI/Au nanohybrids. (d) The value of Zeta potential of GO, rGO-COOH, rGO/PEI, rGO/PEI/Au nanohybrids S6

Figure S4. (a) UV-vis absorption spectra of TMB for each detection system ..S7

Figure S5. XPS wide survey spectra of $\mathrm{rGO} / \mathrm{PEI} / \mathrm{Au}$ nanohybrids after the addition of $\mathrm{Cr}^{6+}$ .S8

Figure S6. PL fluorescence spectra of terephthalic acid of TMB- $\mathrm{H}_{2} \mathrm{O}_{2}-\mathrm{rGO} / \mathrm{PEI} / \mathrm{Au}$ nanohybrids system before and after the addition of $10 \mu \mathrm{M} \mathrm{Cr}{ }^{6+}$ S8

Figure S7. Effects of differrent experimental conditions reaction on catalytic oxidation of TMB. S9

Figure S8. UV-vis absorption spectra of TMB due to the different peroxidase mimetic activity of rGO/PEI/Au nanohybrids stimulated by various ions and molecules S 10

Figure S9. The UV-vis absorption spectra of the new visual chemosensor for $\mathrm{Cr}^{6+}$ and other interfering metal ions and molecules S10

Figure S10. The UV-vis absorption spectra of the real samples reaction system. S11

Figure S11. Comparison of experimental and theoretical absorbance at $652 \mathrm{~nm}$ of TMB for detecting $\mathrm{Cr}^{6+}$ with chromium standard solution. .S11 


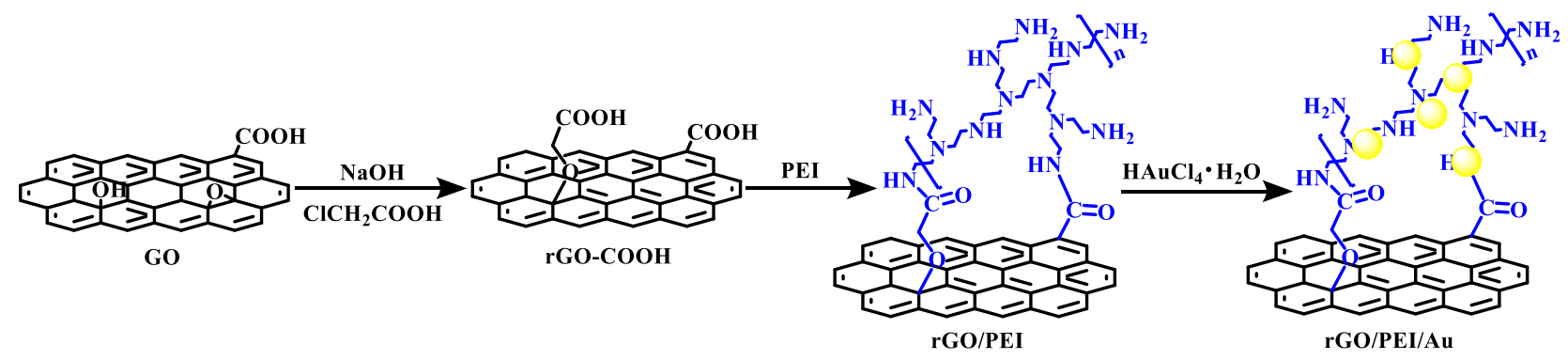

Scheme S1. The synthetic route of $\mathrm{rGO} / \mathrm{PEI} / \mathrm{Au}$ nanohybrids. 


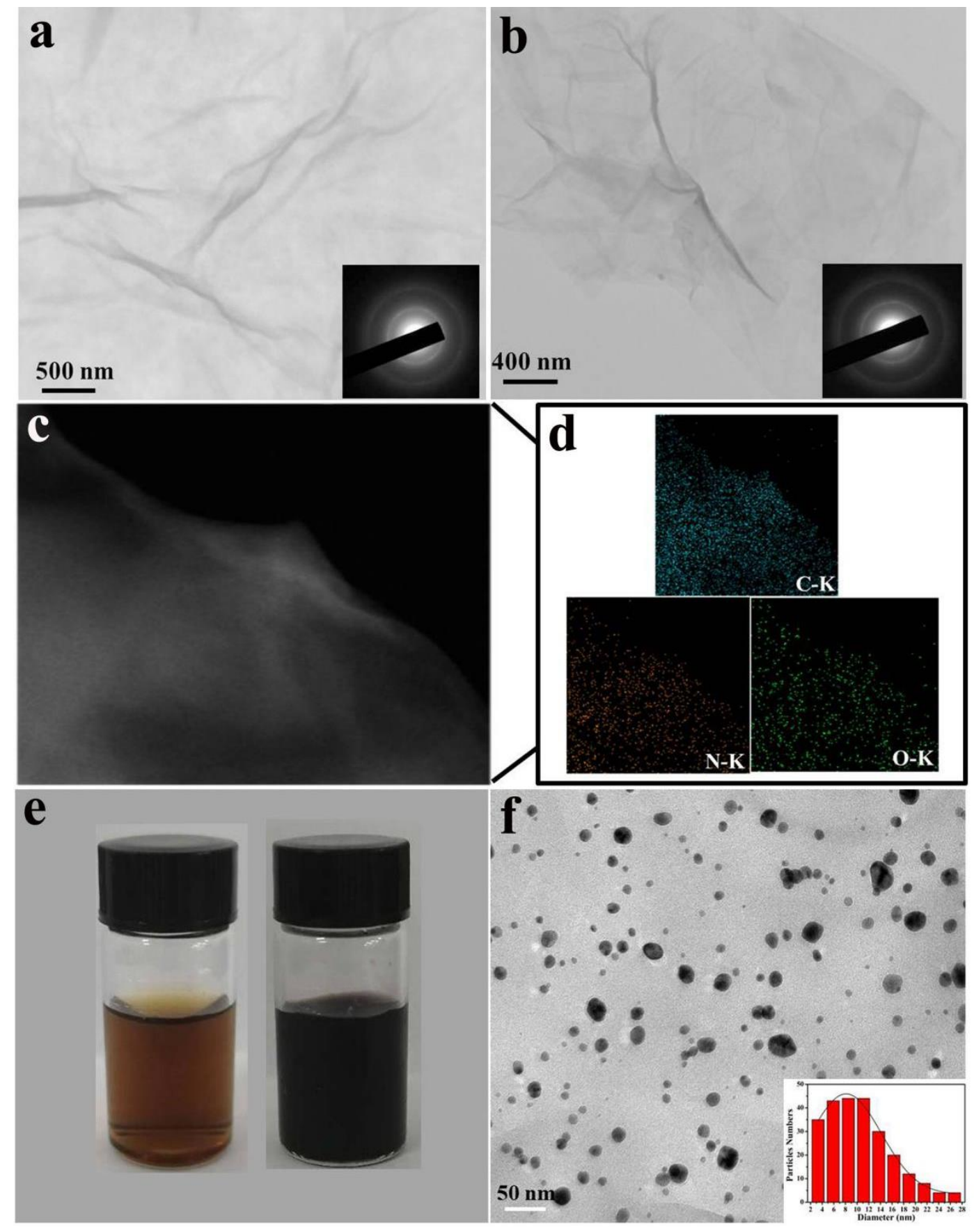

Figure S1. (a) TEM image of GO and SAED pattern of GO nanosheets. (b) TEM image of rGO/PEI and SAED pattern of rGO/PEI nanosheets. (c) Dark field STEM image and (d) element mapping images of rGO/PEI nanosheets. (e) Photographs of GO nanosheets and the rGO/PEI/Au nanohybrids in ultrapure water. (f) TEM images of the rGO/PEI/Au nanohybrids, inset: the nanoparticle size distribution of Au NPs on rGO sheets. 

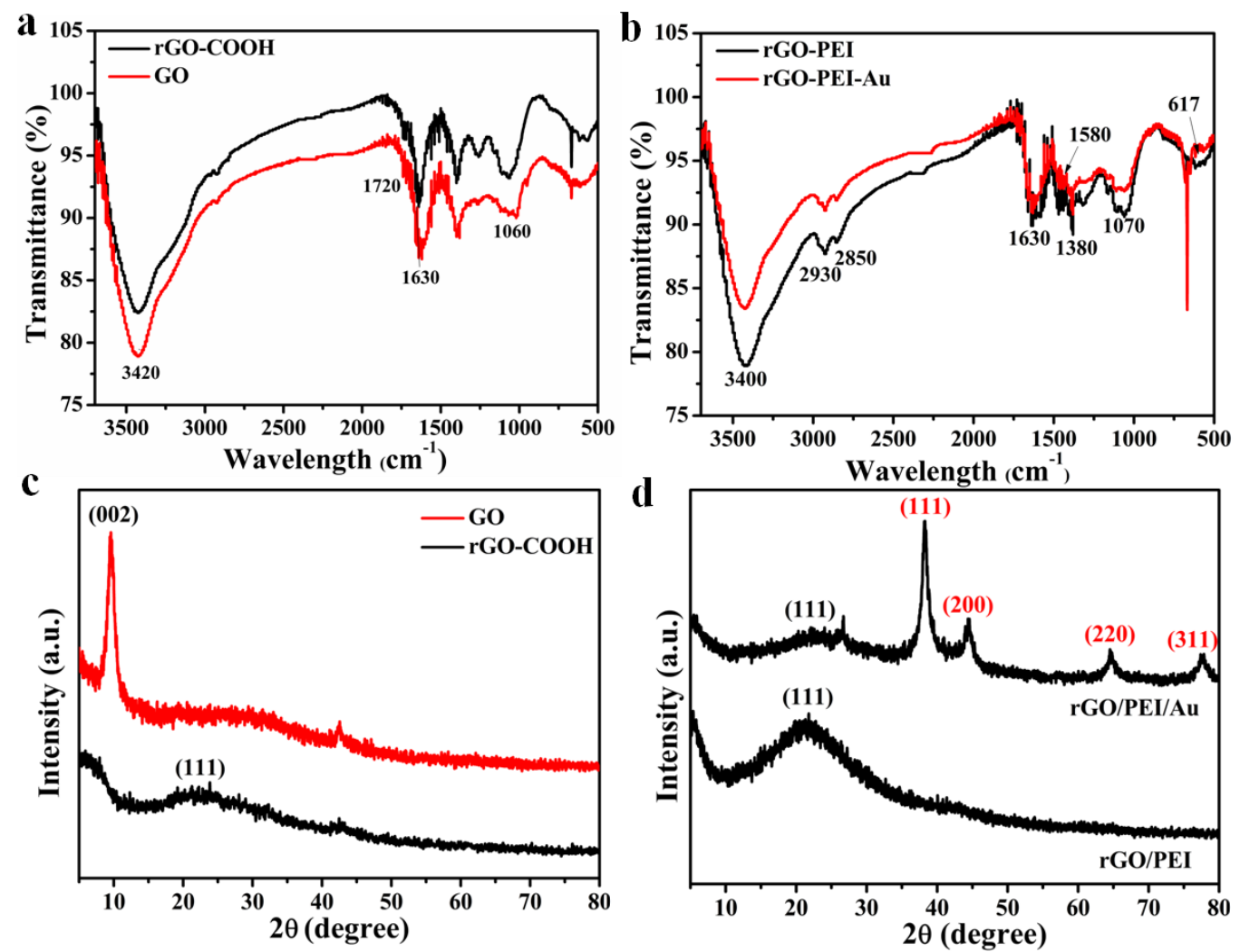

Figure S2. (a) FT-IR spectrum of GO and rGO-COOH nanohysheets and (b) rGO-PEI nanohysheets and rGO/PEI/Au nanohybrids. (c) XRD patterns of the GO and rGO-COOH nanohysheets and (d) XRD patterns of the rGO/PEI nanohysheets and rGO/PEI/Au nanohybrids.

In FT-IR of Figure S2a, $3420 \mathrm{~cm}^{-1}$ belongs to $-\mathrm{OH}$ stretching vibration, $1630 \mathrm{~cm}^{-1}$ is attributed to $\mathrm{C}=$ $\mathrm{C}$ skeleton vibration absorption on the $\mathrm{GO}$ nanosheets. The $\mathrm{C}-\mathrm{O}$ stretching vibration absorption peak in the alkoxy functional group appears near $1060 \mathrm{~cm}^{-1}$. In the infrared spectrum of carboxylated graphene oxide, we can see that the intensity of the hydroxyl vibrational absorption peak $\left(3420 \mathrm{~cm}^{-1}\right)$ is weakened, moreover,XRD and Raman can also prove the formation of rGO-COOH. In FT-IR of Figure S2b, it can be seen the absorption peaks at $1380 \mathrm{~cm}^{-1}$ (O-H deformation vibration), $1070 \mathrm{~cm}^{-1}$ (CO stretching vibration peak in epoxy functional group) and other positions have significant enhancement. In addition, a characteristic peak of PEI appears at $2930 \mathrm{~cm}^{-1}$ and $2850 \mathrm{~cm}^{-1}$. 

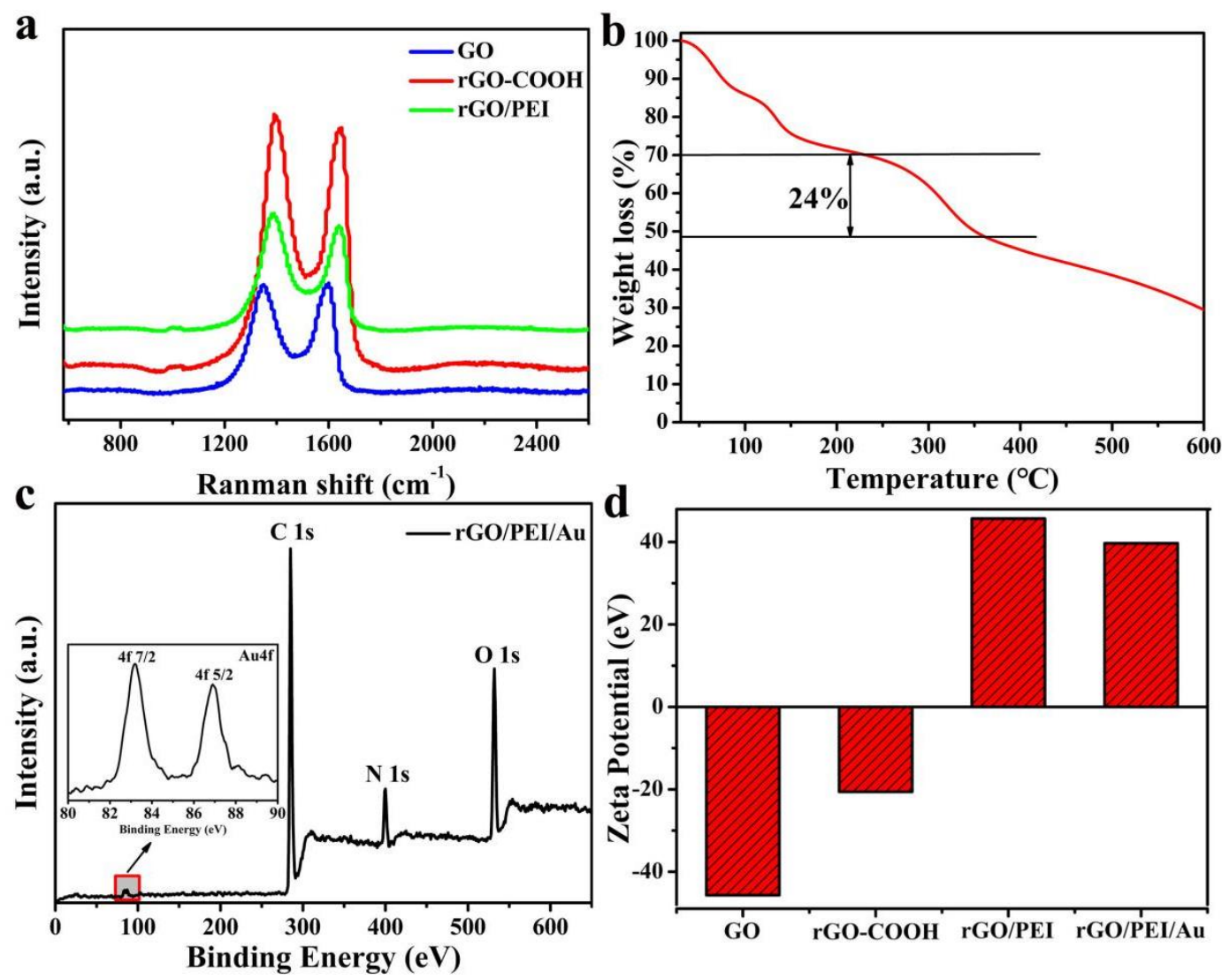

Figure S3. (a) Raman spectra of GO, rGO-COOH and rGO/PEI nanohysheets. (b) TG-DTA spectra of rGO/PEI nanohysheets. (c) XPS wide survey spectra of the rGO/PEI/Au nanohybrids, (insert: XPS spectra of Au $4 \mathrm{f}$ region in rGO/PEI/Au nanohybrids. (d) The value of Zeta potential of GO, rGO-COOH, rGO/PEI, rGO/PEI/Au nanohybrids. $\mathrm{GO}, \mathrm{rGO} / \mathrm{PEI} / \mathrm{Au}$ were dissolved in the water, $\mathrm{rGO} / \mathrm{PEI}$ were dissolved in ethyl alcohol, $\mathrm{rGO}-\mathrm{COOH}$ was dissolved in the DMSO respectively.

In Raman spectrum of Figure S3a, we can observe that GO has obvious characteristic absorption peaks at the positions of $1350 \mathrm{~cm}^{-1}$, (D peak) and $1580 \mathrm{~cm}^{-1}$ (G peak). rGO-COOH, rGO-PEI maintain the main peak shape of graphene oxide, but the characteristic Raman frequency is slightly shifted from graphene oxide. By calculation, the ID / IG values of GO, rGO-COOH, and rGO-PEI are as followed: $0.978,1.053$, and 1.130 , which are gradually increased, indicating that enhanced disorder within the material, confirming successful modification of GO. We can see from the TG-DTA spectra of rGO/PEI nanohysheets in Figure S3b, PEI is thermally decomposed during $210-360{ }^{\circ} \mathrm{C}$, the mass lost between the two platforms is the content of PEI. 

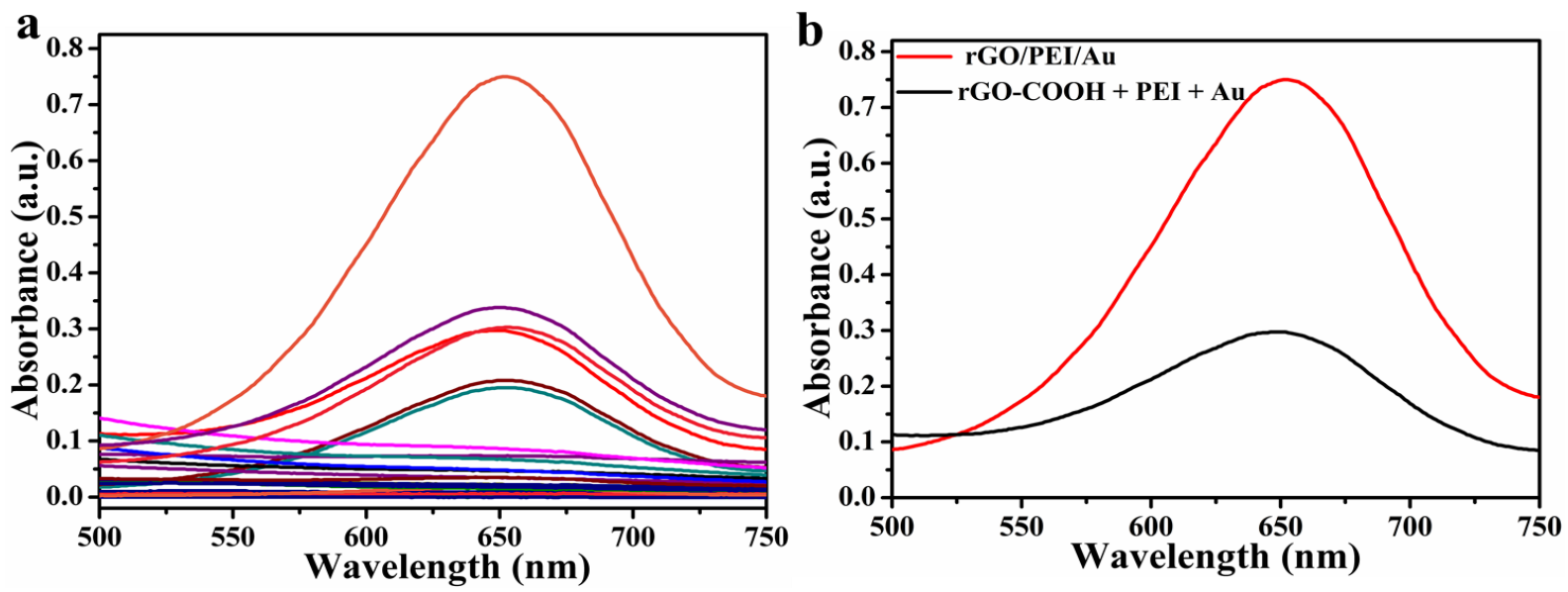

Figure S4. (a) UV-vis absorption spectra of TMB for each detection system. The contained reactants of the each reaction system in figure (a) from 1 to 28 are (1) TMB; (2) $\mathrm{TMB}+\mathrm{H}_{2} \mathrm{O}_{2}$; (3) $\mathrm{TMB}+\mathrm{Cr}^{6+}$; (4) $\mathrm{TMB}+\mathrm{H}_{2} \mathrm{O}_{2}+\mathrm{Cr}^{6+}$; (5) $\mathrm{TMB}+\mathrm{Au}$ NPs; (6) $\mathrm{TMB}+\mathrm{H}_{2} \mathrm{O}_{2}+\mathrm{Au}$ NPs; (7) TMB+Au NPs $+\mathrm{Cr}^{6+}$; (8) TMB+Au NPs+H $\mathrm{H}_{2} \mathrm{O}_{2}+\mathrm{Cr}^{6+}$; (9) TMB+PEI; (10) $\mathrm{TMB}+\mathrm{H}_{2} \mathrm{O}_{2}+\mathrm{PEI}$; (11) $\mathrm{TMB}+\mathrm{PEI}+\mathrm{Cr}^{6+}$; (12) $\mathrm{TMB}+\mathrm{H}_{2} \mathrm{O}_{2}+\mathrm{PEI}+\mathrm{Cr}^{6+}$; (13) $\mathrm{TMB}+\mathrm{rGO}-\mathrm{COOH}$; (14) $\mathrm{TMB}+\mathrm{rGO}-$ $\mathrm{COOH}+\mathrm{H}_{2} \mathrm{O}_{2} ; \quad$ (15) $\mathrm{TMB}+\mathrm{rGO}-\mathrm{COOH}+\mathrm{Cr}^{6+} ;$ (16) $\mathrm{TMB}+\mathrm{rGO}-\mathrm{COOH}+\mathrm{H}_{2} \mathrm{O}_{2}+\mathrm{Cr}^{6+} ;$ (17) $\mathrm{TMB}+\mathrm{PEI} / \mathrm{Au} ; \quad$ (18) $\mathrm{TMB}+\mathrm{PEI} / \mathrm{Au}+\mathrm{H}_{2} \mathrm{O}_{2} ; \quad$ (19) $\mathrm{TMB}+\mathrm{PEI} / \mathrm{Au}+\mathrm{Cr}^{6+} ; \quad$ (20) $\mathrm{TMB}+\mathrm{PEI} / \mathrm{Au}+\mathrm{H}_{2} \mathrm{O}_{2}+\mathrm{Cr}^{6+} ;$ ；21） TMB+rGO/PEI; (22) $\mathrm{TMB}+\mathrm{rGO} / \mathrm{PEI}+\mathrm{H}_{2} \mathrm{O}_{2} ;(23) \mathrm{TMB}+\mathrm{rGO} / \mathrm{PEI}+\mathrm{Cr}^{6+}$; (24) $\mathrm{TMB}+\mathrm{rGO} / \mathrm{PEI}+\mathrm{H}_{2} \mathrm{O}_{2}+\mathrm{Cr}^{6+}$; (25) $\mathrm{TMB}+\mathrm{rGO} / \mathrm{PEI} / \mathrm{Au}$; (26) $\mathrm{TMB}+\mathrm{rGO} / \mathrm{PEI} / \mathrm{Au}+\mathrm{H}_{2} \mathrm{O}_{2}$; (27) $\mathrm{TMB}+\mathrm{rGO} / \mathrm{PEI} / \mathrm{Au}+\mathrm{Cr}^{6+}$; (28) $\mathrm{TMB}+\mathrm{rGO} / \mathrm{PEI} / \mathrm{Au}+\mathrm{H}_{2} \mathrm{O}_{2}+\mathrm{Cr}^{6+}$ respectively. (b) Comparison of peroxides mimetic activity between physically mixing rGO-COOH, PEI, Au compound and chemical bond-rGO/PEI/Au nanohybrids. Experiments conditions: Au NPs, $18 \mathrm{nM}, \mathrm{GO}, 0.025 \mathrm{mg} / \mathrm{mL}$; rGO-COOH, 0.025 mg/mL; PEI: $0.1 \mathrm{mg} / \mathrm{mL}$; PEI/Au: $0.1 \mathrm{mg} / \mathrm{mL}$; rGO/PEI, $0.025 \mathrm{mg} / \mathrm{mL}$; $\mathrm{Cr}^{6+}, 10 \mu \mathrm{M}$; TMB, $0.1 \mathrm{mM} ; \mathrm{H}_{2} \mathrm{O}_{2}, 0.1 \mathrm{M}$, in ultrapure water, incubation time, $2 \mathrm{~min}$; room temperature. 


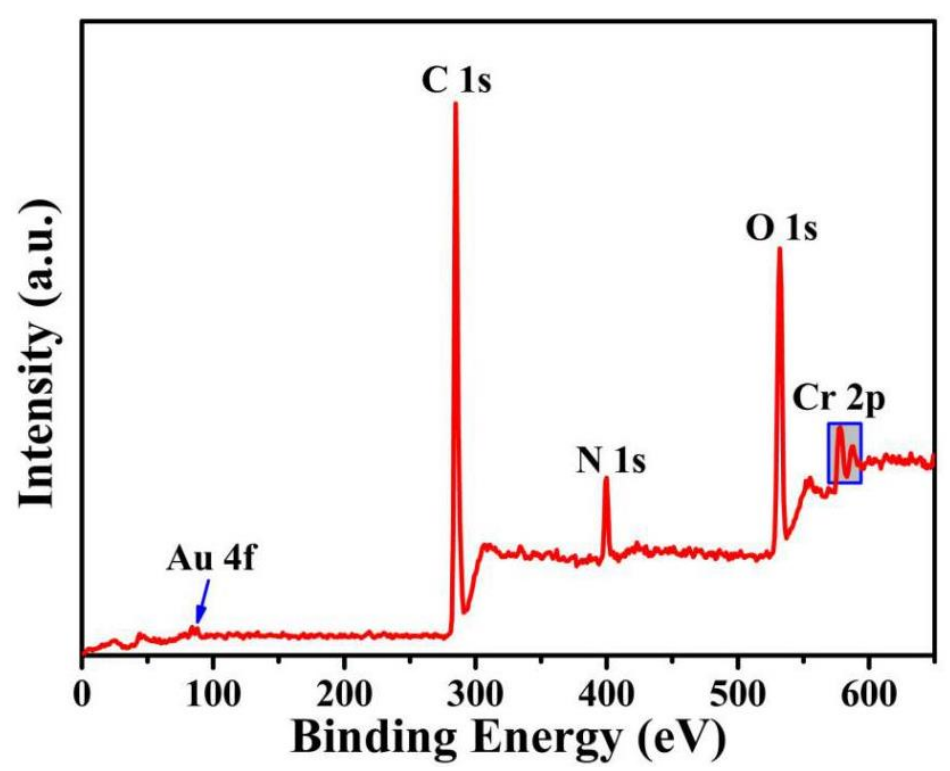

Figure S5. XPS wide survey spectra of rGO/PEI/Au nanohybrids after the addition of $\mathrm{Cr}^{6+}$.

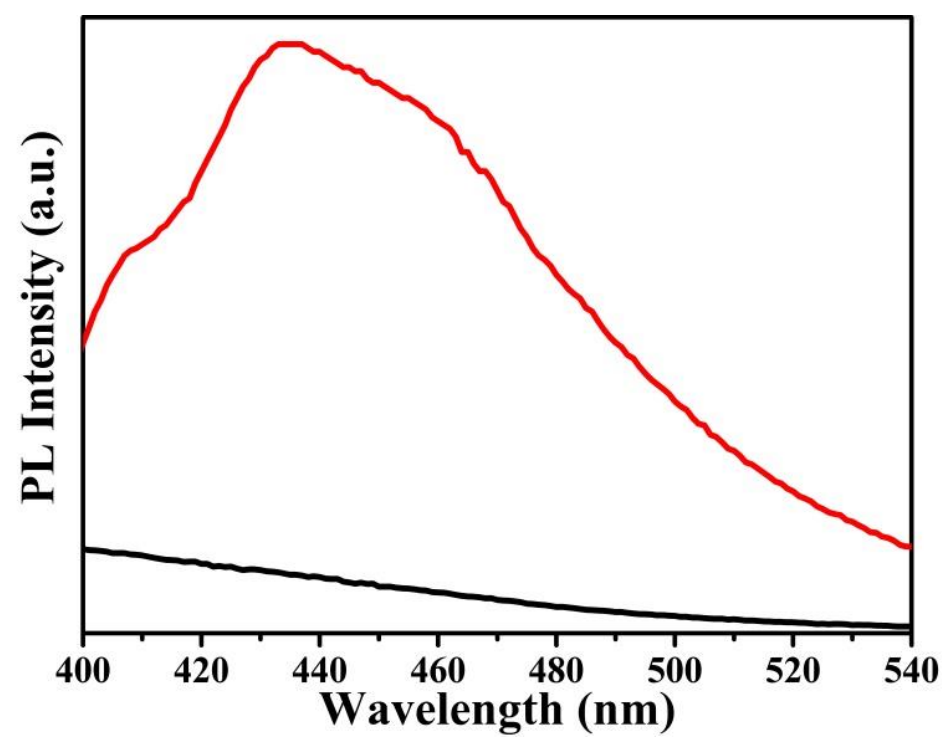

Figure S6. PL fluorescence spectra of terephthalic acid of TMB- $\mathrm{H}_{2} \mathrm{O}_{2}-\mathrm{rGO} / \mathrm{PEI} / \mathrm{Au}$ nanohybrids system before (black line) and after (red line) the addition of $10 \mu \mathrm{M} \mathrm{Cr}^{6+}$. 

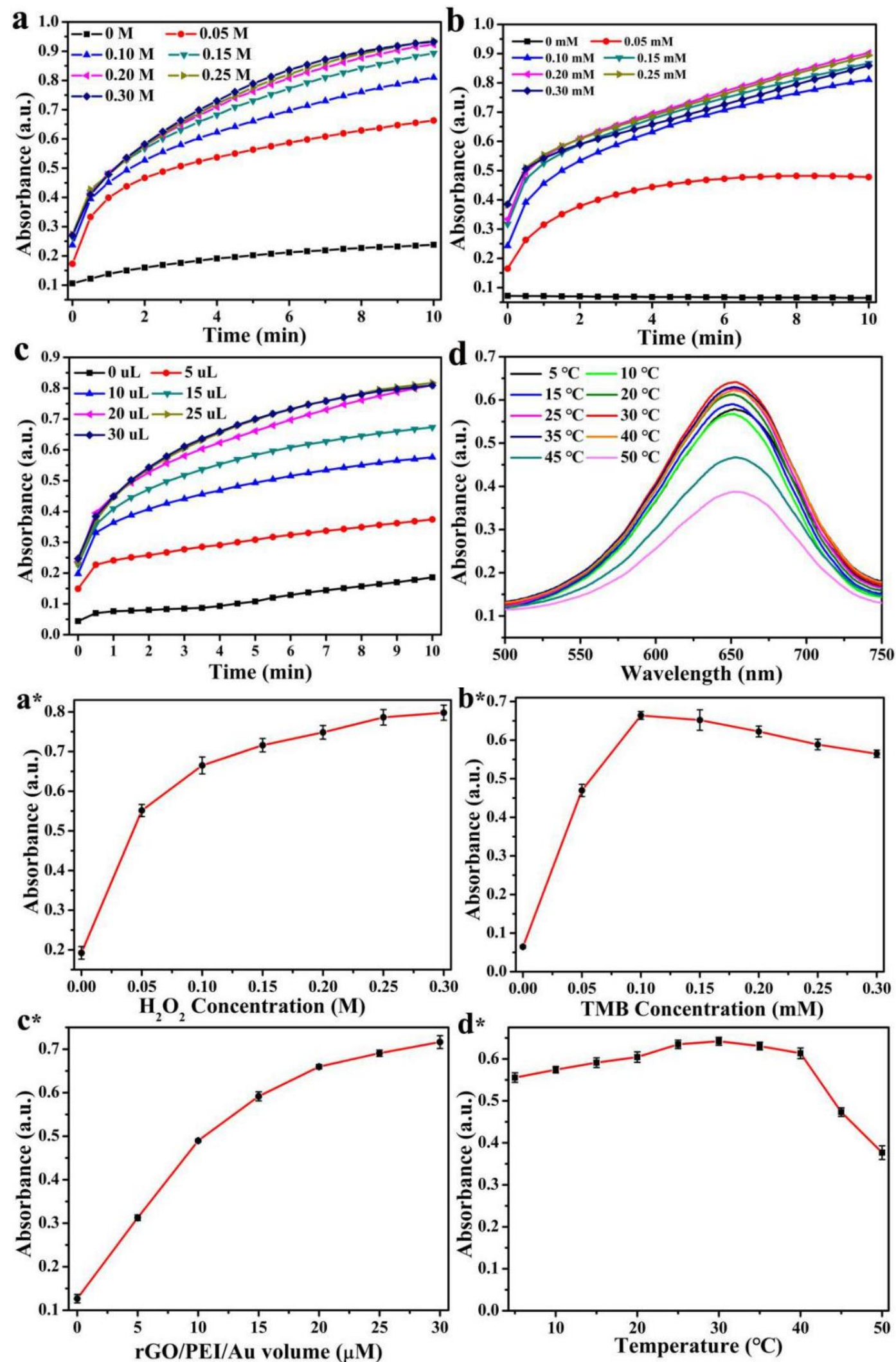

Figure S7. Effects of differrent experimental conditions reaction on catalytic oxidation of TMB. (a) $\mathrm{H}_{2} \mathrm{O}_{2}$ concentration , (b) TMB concentration, (c) rGO/PEI/Au volume, (d) temperature. And Time-dependent absorbance *) $\mathrm{H}_{2} \mathrm{O}_{2}$ concentration, (b*concentration, $\left(c^{*}\right) \mathrm{rGO} / \mathrm{PEI} / \mathrm{Au}$ volume, $\left(\mathrm{d}^{*}\right)$ Effect of reaction temperature on catalytic oxidation of TMB. 


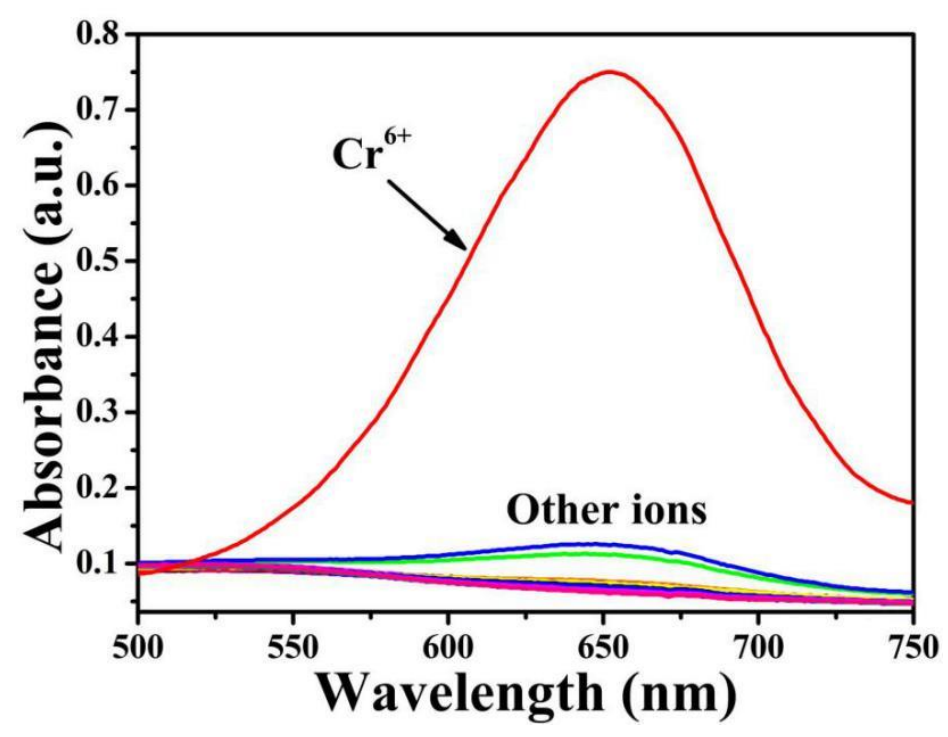

Figure S8. UV-vis absorption spectra of TMB due to the different peroxidase mimetic activity of rGO/PEI/Au nanohybrids stimulated by various ions and molecules.

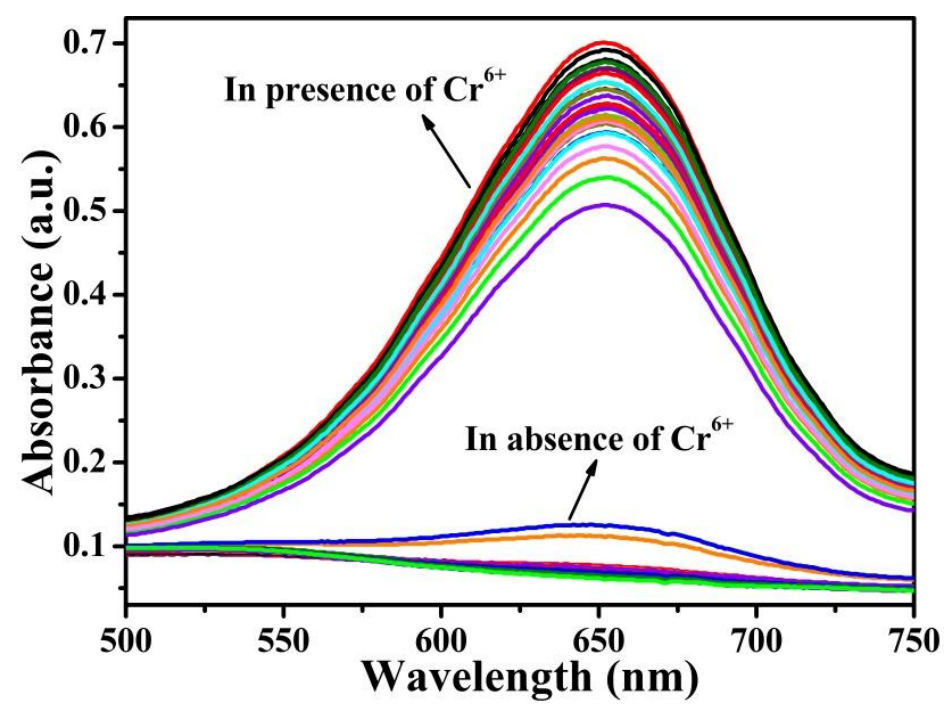

Figure S9. The UV-vis absorption spectra of the new visual chemosensor for $\mathrm{Cr}^{6+}$ and other interfering metal ions and molecules. The metal ions and molecules in the figure from 1 to 34 are $\mathrm{K}^{+}, \mathrm{Na}^{+}, \mathrm{Li}^{+}, \mathrm{Ag}^{+}, \mathrm{NH}_{4}^{+}, \mathrm{Ni}^{2+}, \mathrm{Cu}^{2+}, \mathrm{Ca}^{2+}, \mathrm{Mn}^{2+}$, $\mathrm{Hg}^{2+}, \mathrm{Zn}^{2+}, \mathrm{Co}^{2+}, \mathrm{Fe}^{2+}, \mathrm{Pb}^{2+}, \mathrm{Ba}^{2+}, \mathrm{Fe}^{3+}, \mathrm{Ce}^{3+}, \mathrm{Cr}^{3+}, \mathrm{Al}^{3+}, \mathrm{OH}^{-}, \mathrm{Cl}^{-}, \mathrm{NO}_{3}{ }^{-}, \mathrm{CO}_{3}{ }^{2-} \mathrm{SO}_{4}{ }^{2-}, \mathrm{PO}_{4}{ }^{3-}, \mathrm{SO}_{3}{ }^{2-}, \mathrm{HCO}_{3}{ }^{-}, \mathrm{H}_{2} \mathrm{PO}^{4-}$, $\mathrm{HPO}_{4}{ }^{2-}, \mathrm{C}_{2} \mathrm{H}_{3} \mathrm{O}_{2}{ }^{-}$and molecules $\left(\mathrm{C}_{2} \mathrm{H}_{2} \mathrm{O}_{2}\right.$, glucose, urea and AA) successively.. 

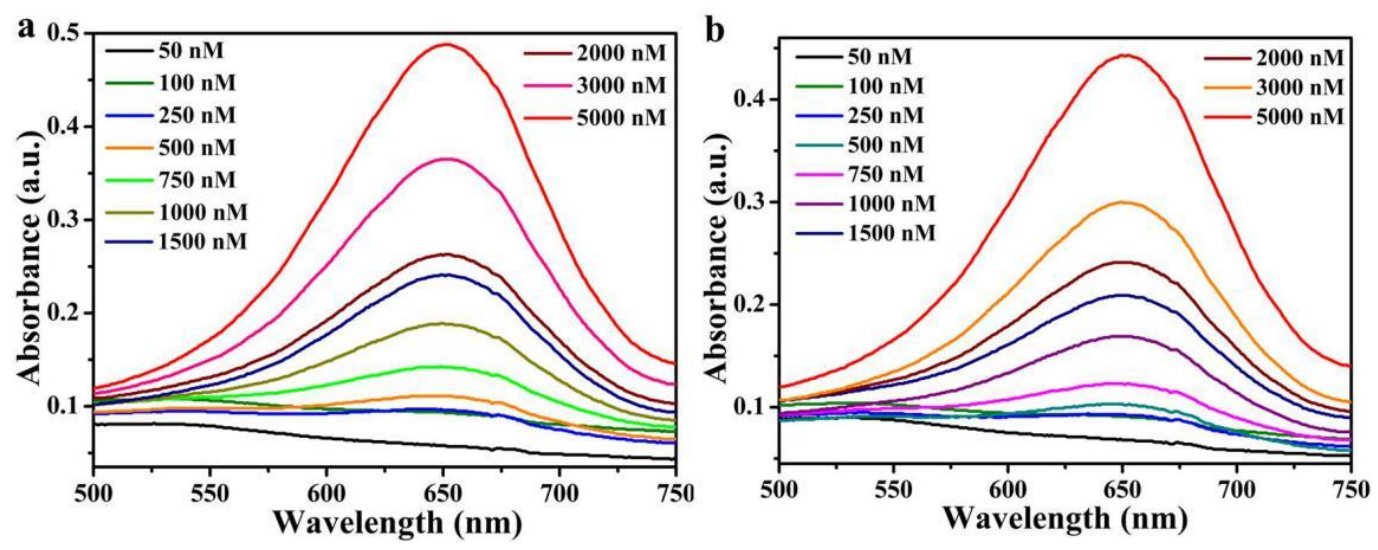

Figure S10. The UV-vis absorption spectra of the real samples reaction system (a) in tap water and (b) in lake water.

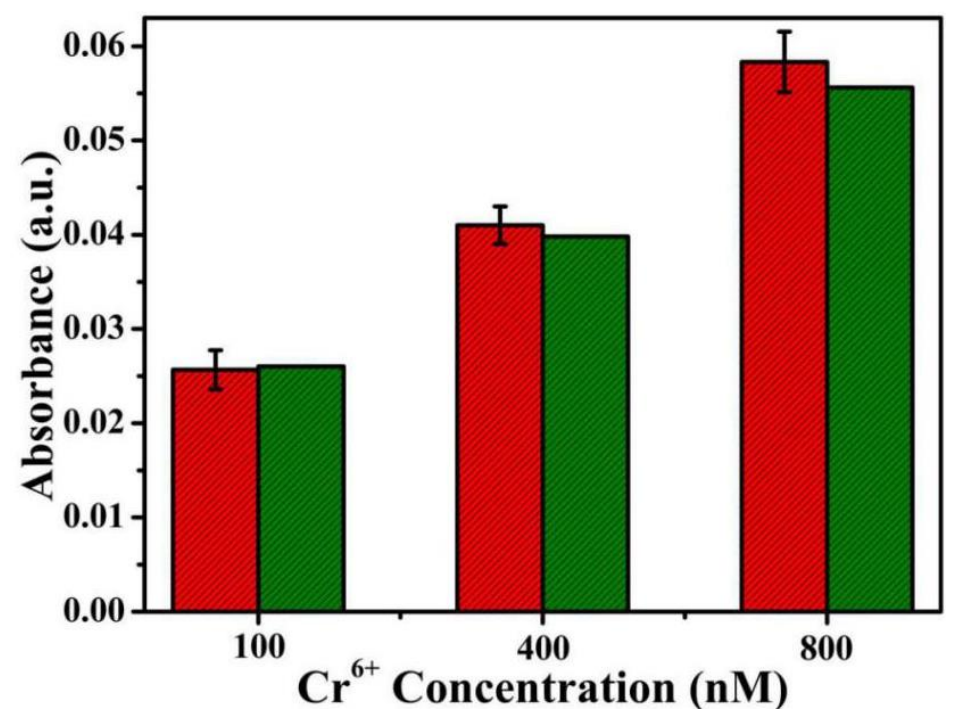

Figure S11. Comparison of experimental and theoretical absorbance at $652 \mathrm{~nm}$ of TMB for detecting $\mathrm{Cr}^{6+}$ with chromium standard solution.(The red histograms represent experimental absorbance at $652 \mathrm{~nm}$ of TMB, The green histograms represent theoretical absorbance at $652 \mathrm{~nm}$ of TMB.) 